\title{
Gambling economics and management: Some insights into recent developments in gambling-related research
}

\author{
Levi Pérez* \\ Department of Economics, University of Oviedo, Oviedo, Spain
}

Received: 15 November 2018

Accepted: 15 November 2018

\begin{abstract}
There are several arguments why the economic and management analysis of gambling seems to be very interesting. Gambling is a relevant worldwide market from which either local or national governments obtain resources due to some sort of fiscal imposition on gambling participation. On the other hand, gambling is also a social phenomenon with potential risks to society and the consumption of gambling seems to violate the premises of economic theory (risk aversion, maximizing and rational conduct). The aim of this special issue is to provide an outlet for recent developments in gambling-related research encompassing topics on sports betting, responsible gambling, lottery markets and online gambling, among others.
\end{abstract}

Keywords: gambling; sports betting; lottery

JEL Classification Codes: D12, H27, L83

\section{Introduction}

The gambling industry is experiencing a scenario of both growth and consolidation favoured by technological improvements and the willingness of many governments to encourage the development of this industry through an efficient and proactive regulatory framework. As a result, this activity has become one of the markets with the greatest potential for short-term economic growth.

In general, governments appear to trade off the negative aspects of gambling (addiction, compulsive gambling, fraud, corruption, etc.) and the revenues that can be gained by regulating and taxing this activity. Sauer (2001) explains the regulation and availability of gambling activities in the context of a public choice model and Simmons (2008) points out that availability of gambling activities can be explained in terms of friction between certain lobbies or pressure groups, consumers, who view gambling as entertainment, and governments. The potential effects of expanding gambling opportunities may have to be balanced against the risky consequences of these activities.

\footnotetext{
*E-mail: 1perez@uniovi.es.
}

Citation: Pérez, L. (2018) Gambling economics and management: Some insights into recent developments in gambling-related research, Economics and Business Letters, 7(4), 126-128. 
Given the global expansion of gambling opportunities, the interest in the field of social sciences in this leisure activity has been growing rapidly. Economists, sociologists and psychologists, among others, have studied this industry at length, and have found it to be much more complex than it may appear at first glance. So, there is still a market for research related to strategic issues in gambling including recent trends and current policy concerns.

\section{Contributions}

The contributions in this special issue cover a wide range of topics in recent developments in gambling-related research including: a useful contribution to the literature on the subject of betting markets that investigates the movements of major betting companies in European football focusing on two current issues: declining over-round and increasing arbitrage opportunities; an examination of how betting experience is associated with bettor's sequential risk taking; a complete picture of the relationship between gamblers' perception of the organization's commitment to responsible gambling programs and satisfaction with the firm; a discussion of the state of the literature on how to set the parameters of a lotto game so as to maximize revenue to the state; and a detailed literature review of the motivations for regulating gambling.

\subsection{The betting market over time: Overround and surebets in European football}

This contirbution builds upon existing literature to discuss the overround in the betting market and how it has fallen over time. It extends previous research by Che et al. (2017) by looking at betting on matches in different leagues over a longer time. Even though the result is not surprising as competition and technology should drive prices in these betting markets down overtime, the study does illustrate by how much and how quickly this has occurred, which is an important insight. Beyond this finding, the biggest contribution of the paper is the increased level of surebets in the last few years, which sheds additional insights into how sportsbook managers are (and are not) operating in this industry.

\subsection{Does betting experience matter in sequential risk taking in horse race wagering?}

The paper builds on Suhonen and Saastamoinen (2018), where it is documented that prior gains and losses impact risk taking of horse race bettors. In the present paper, the authors test for differences between experienced and inexperienced bettors on this issue. The paper finds that it is inexperienced bettors that account for increased risk-taking following wins, and experienced bettors that account for decreased risk-taking following losses. The finding that gambling behaviour is influenced by experience is interesting and important.

\subsection{The relation between responsible gambling program perceptions and customer satisfaction with a gambling firm}

Exploring the association between the perceptual factors of responsible gambling program and customer satisfactory in a gambling firm is an interesting theme that has not fully understood yet. This study examines the association (i.e. correlation) between perceptual factors of a responsible gambling program and customer satisfaction, providing a complete picture of this relation.

\subsection{The optimal structure of lotto games}

Domestic lotto games in many jurisdictions worldwide have experienced a significantly decline in both sales and revenues. In an attempt to reverse this trend, lottery operators conducted major structural reforms on games' design. Thus, the analysis of the impact of product innovation on lottery sales is a very current topic. This paper aims to bring together the literature in order to brief readers on the economics behind choosing the several game parameters which define a lotto game. 


\subsection{Regulation of online gambling}

This paper focuses on idiosyncrasies of online gambling and provides some examples of current (different) types of regulation. It also reviews the motivations for regulating gambling, and provides a detailed literature review

\section{Concluding remarks}

It appears evident that the potential value of gambling related markets may be increased, but these benefits should be balanced with the potential risks to society from this activity (gambling-related harm). A deep knowledge and understanding of this industry and the establishment of the appropriate regulatory framework would be crucial in any case. It is hoped that this special issue demonstrates the richness and depth of contemporary research into gambling markets and that the findings here would be helpful for gambling researchers, regulators and policy makers.

\section{Acknowledgements}

I would like to acknowledge all authors for their efforts in submitting high-quality papers to this special issue. I am also very grateful to the reviewers for their thorough and on time reviews of the papers.

\section{References}

Che, X., Feddersen, A., and Humphreys, B. (2017) Price setting and competition in fixed odds betting markets. In Rodríguez, P., Humprheys, B., and Simmons, R. (editors), The Economics of Sports Betting, Edward Elgar Publishing: Cheltenham.

Sauer, R. (2001) The political economy of gambling regulation, Managerial and Decision Economics, 22(1-3), 5-15.

Simmons, R. (2008) Prohibition of gambling. In Meadowcroft, J. (editor), Prohibitions (Readings in Economics), Institute of Economic Affairs: London.

Suhonen, N., and Saastamoinen, J. (2018) How Do Prior Gains and Losses Affect Subsequent Risk Taking? New Evidence from Individual-Level Horse Race Bets, Management Science, 64(6), 2797-2808. 